\title{
“THERMODYNAMICS IS NOT A SPECTATOR SPORT!" [7] AN EXPLORATORY STUDY ON INCORPORATING ACTIVE LEARNING INTO A FIRST YEAR THERMODYNAMICS COURSE
}

\author{
Jillian Seniuk Cicek, Douglas Ruth and Sandra Ingram \\ Faculty of Engineering, University of Manitoba, Winnipeg, MB, Canada R3T 5V6 \\ Corresponding author E-mail address: umseniuk@cc.umanitoba.ca
}

\begin{abstract}
Student engagement is deemed as one of the fundamental components of consequential learning. Essentially, contextualizing information in authentic events and situations and designing active learning experiences to orchestrate opportunities for students to construct their own knowledge are ways to engage students in their own learning process. This paper reports on a Professor's efforts to turn a traditional, lecturebased first year Thermodynamics course into an active learning arena. The study uses a qualitative approach to data collection and analysis, with data amassed through participant observations and open-ended interviews with the Professor. A number of categories and themes have already emerged. This paper outlines the category, Instructional Strategies, and discusses how they were modified and/or amplified to incorporate active learning in an attempt to further engage students.
\end{abstract}

Keywords: active learning; student engagement; instructional strategies; qualitative research

\section{INTRODUCTION}

Consequential learning enables today's engineering students to gain the knowledge and skills, and form the values and behaviours required to become experts in their fields in the 21 st century [12][20]. The capability to access and transfer knowledge from one context to another is a key factor in becoming an expert [12]. Being able to function with real world challenges in real world situations is an integral part of engineering [25]. Researchers have found that "The main problem within engineering education is the gap between the active field and the passive classroom experience" [25]. Traditional engineering classes tend to be deductive, and can lead to an inactive classroom. Deductive teaching is not an especially successful motivator [18]. Today's instructors are called on to activate students, becoming "less an imparter of knowledge and more a designer and facilitator of learning experiences and opportunities" [20].

Supporters of active/inductive pedagogy hold that "To teach is to engage students in learning" [20], and "the real challenge in college teaching is not covering the material for the students; it's uncovering the material with the students" [20]. When instructors present information without contextualizing the knowledge in authentic experiences and orchestrating opportunities for students to construct their own learning, there is the potential for students to disengage. These ideas can be linked to the work of John Dewey, who "suggested that educators needed to encourage inquiry and that education should be grounded on experience and linked to real-life activities in order to motivate and develop students" [25].

A Dean Emeritus at a large research university in western Canada has developed a philosophy of education based on his years of experience dealing with undergraduate students and his belief that engineers like to be active. His theory is that students come to the program in first year already equipped with engineering personalities; they just need the opportunity to develop the knowledge, skills, abilities, values and behaviours inherent to the profession. From this process, like chrysalises, engineers will eventually emerge.

The Professor was convinced that the first year engineering course that he taught, ENG 1460 Introduction to Thermal Science, would have far more appeal and produce a better learning environment if he could just use an experimental apparatus to model some of the processes that were being demonstrated vis-à-vis two-dimensional drawings and equations. "When we get the experimental apparatus it's going to be... a lot different... that will be definitely active, that will be active learning." The Professor believes engineers need to see how things were done: "[if] they can see it, they can believe it and if they can believe it they can do these problems." He had already begun to use some active instructional methods with students, such as the i-clicker, and wanted to test if they were working.

The Professor retained an engineering education $\mathrm{PhD}$ student from the faculty to conduct a pilot study. The research plan was built around the Professor's interest to integrate more active learning into his classroom, which in theory should increase student engagement and thereby, student learning [2][6][20]. The objectives were: (i) to investigate the Professor's instructional strategies to incorporate active learning and encourage student engagement; and (ii) to make improvements to these strategies to increase active learning and student engagement.

Informed by engineering education literature on active learning and student engagement [2][6][18][20][25], guided by "hunches" and professional judgment, and strengthened by the process of conducting cycles of 
participant observations and open-ended interviews with the Professor to facilitate reflection, strategies were mapped out for inserting active learning into ENG 1460. They were to: (1) scaffold learning; (2) use a gradual release model; (3) use big picture/mapping; (4) experiment with the i-clicker; (5) facilitate students solving problems in class; (6) facilitate student discussion with peers; (7) make authentic connections for students by providing real life examples; (8) work towards constructing an experimental apparatus for demonstration; (9) reflect on instructional strategies; and (10) treat students like junior engineers to increase student engagement.

Most of these strategies were, through participant observations, already found to be a part of the Professor's repertoire, albeit at times unconsciously. The exception was the strategy, student discussions. The Professor's use of these strategies was observed and then through conversational, open-ended interviews conducted by the researcher, they were modified or expanded to increase active instruction and encourage student engagement. This paper reports on these observations and interviews with the Professor, and the resulting modifications and amplifications of his instructional strategies.

\section{METHODS}

A qualitative approach was chosen for this study because it fit the researcher's exploratory objectives. Qualitative research is an "inquiry of understanding a social or human experience" [5]. It affords the researcher an in-depth view of an experience, from which a detailed picture emerges [5]. The value of qualitative research is that it offers insight into understanding human perspectives and motivations [13]. In contrast, quantitative studies generally offer broad, numerical descriptions of summaries of data [13]. Qualitative and quantitative methods each have distinctive uses, and for the purpose of this research, the more detailed view of the participant and the situation afforded by qualitative research was required in order to meet the study's objectives.

Further, this study was influenced by elements of action research and ethnography. Action research aims are "strategic improvement of practice" [1], which characterize the objectives of this research. It is unique because "improvement occurs through the active engagement of the practitioner" [1], which was facilitated in this work through the chosen data collection methods: participant observations and open-ended interviews with the Professor.

The elements of ethnography are found as the researcher took the role of a participant observer [1], which in this study reflected her participation in the shaping of the Professor's instructional methods (not participation in the classroom). Participation was achieved through the subjective, reflective field notes that the researcher recorded throughout the study, which informed her engagement in the conversational interviews with the Professor and her efforts to guide the increased use of active instructional strategies to foster student engagement (as opposed to her assuming a more characteristically quantitative, objective researcher role [22]). The researcher used her experiences as a teacher/instructor (13 years) as the standpoint from which she viewed and informed the pedagogical decisions taken in the study [22].

Ethnographic research uses "thick description" to categorize and interpret data, and come to an "emerging understanding of the observed activities, and...guide subsequent data collection and analysis" [22]. Data for this study were collected using a repetitive participant observation followed by an open-ended interview cycle. In this way, the participant and the researcher's recurrent reflections and subsequent findings directed the study. The resulting data were analyzed using a qualitative analysis technique characterized by careful, reflective, indepth readings of the data to identify prevalent categories and themes [23][26]. The emergent findings are presented narratively, another feature of qualitative research [5].

\subsection{Participant}

The participant in this study was the instructor of ENG 1460 Introduction to Thermal Science, here on referred to as the Professor. The Professor is a Dean Emeritus, former Dean of the Faculty of Engineering, and current NSERC Design Chair. He has been on academic staff for 26 years, and was previously a professor at another large university in western Canada. He spent 8 years as a practicing engineer in the petroleum industry between academic jobs, as well as working in industry for 3 years before attaining his Ph.D. He is the father of 3 grown daughters.

\subsection{Participant observations}

The site of the participant observations was a sizeable engineering lecture hall where a first year ENG 1460 Introduction to Thermal Science course was taught to a large group of students. The room was located in the basement level of a recently renovated engineering building. Approximately 10 built-in long tables ran the width of the room, with seating comprised of moveable plastic and metal chairs. The classroom ascended on an incline toward the back on cement "stairs," so that each table was slightly higher than the one in front. Hallways ran up both sides of the room in a gradually ascending slope starting from the doors at the bottom front of the room. Situated to the right of one door was a built in workstation, complete with electrical and computer hook- 
up. Behind the workstation was a white board. To the left of the white board was a large white screen, on which were projected the class slides from the Professor's computer.

Techniques for participant observations were informed by Creswell and Leyden et al. [3][13]. The researcher sat in a chair at the top of the lecture hall, to the right of the last table and took notes on the Professor's instructional strategies and his methods to engage students. Twentyfour participant observations were completed, resulting in 111 pages of hand-written field notes.

\subsection{Interviews}

Interviews with the Professor were conducted face-toface in his office, and were scheduled after each observation. After the second interview, the researcher received the Professor's permission to record their conversations. A Sony recorder was used, and all audio recordings were transcribed into Word documents. Interviews were open-ended conversations focused on the Professor's instructional strategies and methods to encourage student engagement. Plans were made to improve, extend or incorporate additional active learning strategies and techniques into the Professor's instruction to encourage engagement. Twenty-three interviews were conducted, of which 21 were recorded. Interviews lasted between .5 and 1.5 hours, resulting in 443 pages of typed transcripts. Transcripts ranged from between 7 and 36 pages each.

\section{FINDINGS}

There was a huge generation of data from this study resulting in a number of preliminary findings; too many to discuss here in depth. For this paper, an overview of the instructional strategies mainly supported by the field notes will be presented. The Professor's direct quotes will be indicated by quotation marks; the researcher's reflections will be presented in italics, and her direct quotes signified by both quotes and italics.

\subsection{Instructional Strategies}

Instructional strategies that the Professor was observed using were coded as (1) Traditional; (2) Less Traditional; (3) Inherent to Engineering Educators; and (4) Particular to the Professor [3][19]. Traditional is taken in this paper to mean commonly used in both education and engineering instruction, and less traditional indicates less common in engineering, as opinioned by the Professor. Strategies inherent to engineering educators were distinguished by their dependence on engineering features. Strategies particular to the Professor were characteristic of his personality. These codes emerged from the data [3][22][26] and were grounded in the Professor's and the researcher's experiences.

\subsection{Traditional Strategies}

Traditional strategies were represented by (i) Lectures; (ii) Q \& A (questions and answers); (iii) Problem Solving; and (iv) Course Slides. All of these methods were part of the Professor's teaching repertoire before this study began. However, through participant observations and the resulting discussions, they were modified.

(i) Lectures: This strategy could be considered the Achilles heel of the Professor's methods in that he felt bounded by it. Indeed, it was his discomfort with this passive style of teaching that initiated this study, but he could not see an easy way around it. The Professor felt constrained by class time and the need to cover the material. These are notes taken from the Professor and the researcher's second interview: [We both] Agreed class was less active. One reason: lots of notes on "interpolating" - lots of equations - no activity/participation for students. A plan was made to ease away from constant lecture and into more activity. The idea was to merge lecture and problem solving activities in a "look and listen/learn/do/ learn" approach, rather than limiting problem solving to the once-a-week tutorials. The initial discussion to incorporate this active learning strategy was recorded by the researcher: Discussed how students could follow along, using paper and pencil, calculator, do calculations while [the Professor] walks them through. Then [the Professor could] give another interpolation for pairs of students to do; then homework questions. [Demonstrating the] gradual release model. Discussed how thermodynamics is NOT a spectator's sport!

As an extension of this effort, a Flow Device handout was created that used diagrams and yes/no questions to both activate and scaffold students, leading them through the process of deriving equations for energy transfer systems (see Fig. 1), a topic that had formerly been presented to students purely by lecture.

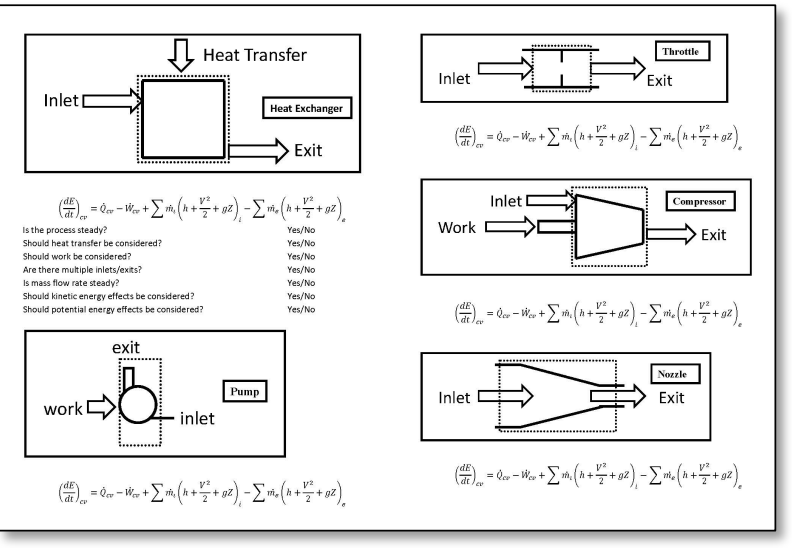


Fig. 1. Example of Flow Device handout.

(ii) $Q \& A$ : Using questions and answers was another traditional strategy that through participant observations and subsequent interviews was amended. At the beginning of the study, the Professor often jumped between using rhetorical and Socratic questioning; however, in his style of instruction, the distinction was not always clear. As the study matured, through the benefit of the discussions and the process of debriefing, the Professor began to use tone, eye contact and wait time to clearly distinguish which style of questioning he was using to engage students. For example, if the Professor wanted students to respond, he would pause after his question: "What does state 2 look like?" Pause. "What do we know?" Pause. "What would happen if...?" Pause. He also began to engage in a survey-style question strategy, where he would probe students' understanding by asking, "By a show of hands, who thinks..." Further, the Professor began to repeat student questions before he answered or redirected them. As described in the methods section, the classroom was large and students sat in rows facing the front. Therefore, a question posed by a student in the front or middle rows often could not be heard in the back. The Professor began to repeat student questions in order to engage all students in the answer or the ensuing discussion.

(iii) Problem Solving: A third strategy used in the course was problem solving. At the beginning of the study, this method was relegated solely to the 3-hour tutorial that was held at the end of each week. The researcher and professor began to strategize ways of inserting problem solving into the lectures. This was done in several ways: (a) students were encouraged to use their "green sheets" (homework sheets for tutorial) in class to write down and solve equations before they were illustrated on the class slides; (b) students were given the Flow Device handout to use as a worksheet; (c) the iclicker was used as a multiple choice problem solving activity. For example, to engage students in problem solving, the Professor would use these directives: "pull out your pencil, and see if you can interpolate - have a go at that one"/ "calculate the volume in the rigid vessel containing air"/ "write out state 1 and state 2"/"write down the equation... see if you have the right one"/"You do the calculation."

(iv) Course Slides: A fourth teaching strategy was found in the use of course slides. These were an excellent visual tool with animated diagrams and equations using arrows, a variety of colours and fonts, and boxed captions to take students through problems and derivations (see Fig. 2). They were made available to students through the Internet. The slides, although already very effective, were modified by the Professor even further to add more animations, accommodating for students' in-class problem solving. As well, new slides were made, and at times access to the slides was delayed so that students were more apt to actively solve equations in class.

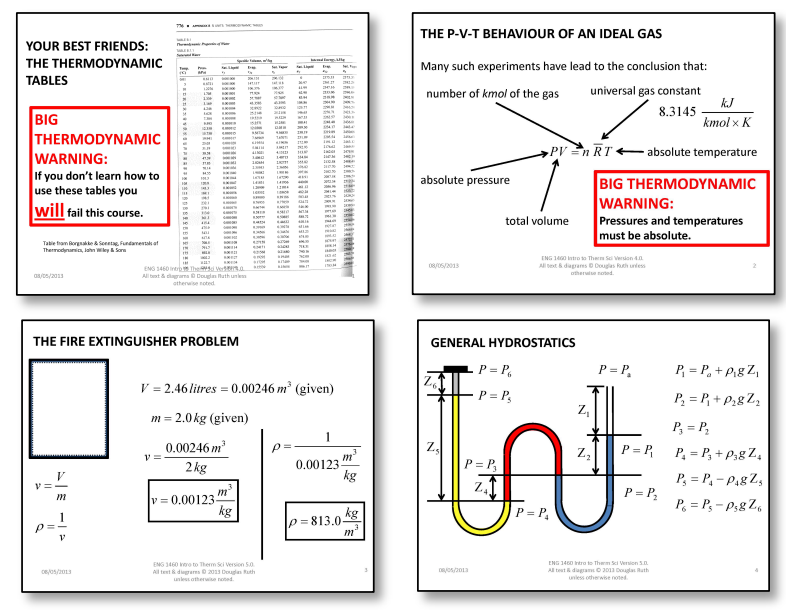

Fig. 2. Examples of course slides.

\subsection{Less Traditional Strategies}

Less traditional strategies included the use of (i) iClickers; (ii) Road Mapping, where the Professor laid out instructional objectives for students; and (iii) "Consult your Neighbour," where opportunities were created for peer discussions.

(i) i-Clicker: The i-clicker was one of the less traditional strategies employed by the instructor before this study began. Its use was modified and extended during this research investigation. i-Clickers are a student response system, and an excellent strategy for engaging students [14][4] and providing instant feedback for both students and instructors. Students are given a group of statements, and can choose the one best suited to them by pressing the corresponding button on their i-clicker. Once students have made their selection, the instructor can display a graph of all the class responses. Students can ask themselves How did I do? How did others do? This encourages them to practice self-reflection, engage in metacognition, and take responsibility for own learning, all facets of the CEAB graduate attribute, Lifelong Learning. The instructor can question: How are my students doing? Should I go over the problem again? What are/were my students' expectations? Did they meet their expectations? In ENG 1460, the Professor put up a slide that had 5 Likert-scale statements describing various levels of student responses to problems, tests or exams. The i-clicker slides were entitled, How are we doing? Students could choose from examples such as: Now that we've done this problem in class, can you do it on your own? (A) I definitely can (B) I think I can (C) I am unsure 
I can (D) I don't think I can (E) I definitely can not. Once students responded, the Professor displayed the class results.

The Professor's use of the i-clicker was discussed with the researcher, and a plan was put into place in the event students' responses showed that they were not getting a problem. It was determined that if less than $65 \%$ of students did not feel strongly about their understanding, (i.e., in selecting $C, D$ or $E$ ), the Professor would go back and do the problem again. The researcher communicated to the Professor that she felt that this would create a sense of trust and confidence in students by demonstrating that their responses affected the Professor's instructional decisions. Further, following more discussion and reflection, the Professor began using the i-clicker for problem solving, asking students for example, What State am I in? (A) Saturated liquid (B) Saturated vapor (C) Saturated mixture (D) Compressed liquid (E) Superheated vapor. The modified and extended use of the i-clicker was used to encourage student engagement.

(ii) Road Mapping: One of the instructional strategies that was evident in the Professor's repertoire is referred to as road mapping. This can be thought of as creating the big picture for students: an overview of instructional intentions so students know where they are going and how they are getting there. For example: "Last time we..." "This time we'll... "Now we're going to..." During the interviews, this method was discussed and encouraged by the researcher. She believed that this would give students some control over their own learning, and thereby increase their engagement. It was also felt that this would be an excellent way for students to demonstrate metacognition, a skill inherent in successful lifelong learning. The Professor extended his use of road mapping to model his own thinking, illustrate his instructional objectives, make the learning required of students transparent, and encourage students' own metacognitive activity. For example, "Today we're going to ask..." "What I am trying to do is..." "We're going to increasingly be solving problems..." "Most engineering problems have this..." "[I'm using the i-clicker because I want to see if] people are picking it up." These tag lines all displayed the teaching strategy, road mapping.

(iii) "Consult your Neighbour": One of the strategies that the Professor adopted as a result of the interviews was his use of peer discussions to solve problems. The researcher noted this in her field notes: After our discussion of pair-share, [the Professor] began asking students - encouraging them - to work together to solve clicker problems. When assigning problem solving sessions in class, the Professor would say, "Please feel free to consult with your neighbour." The use of cooperative learning is supported in the research as engaging for students [20][18]. Using peer discussion was another way for the Professor to depart from the lecture strategy and activate and engage students, a concept that was magnified through the reiterative components of discussion and reflection built into this exploratory study.

\subsection{Strategies Inherent to Engineering Educators}

A strategy the Professor used that was inherent to engineering educators was coded as (i) Modeling How to Think Like an Engineer. This was where the Professor used a think-aloud strategy to demonstrate how he would consider a problem/situation from his perspective as an engineer and what assumptions he would make. The professor would show how engineers approached problems/situations, and how students, as junior engineers per say, should emulate this thinking.

(i) Modeling How to Think Like an Engineer: Fundamental in the Professor's instructional strategies was his use of modeling how to think like an engineer. The researcher queried this approach in the interviews to find out if this was unique to the Professor. He replied that no, other engineers in the faculty "do it really well." Modeling to think like a professional is likely inherent in other professional degrees, and modeling is certainly present and encouraged in educational pedagogy and research [10]. The Professor demonstrated the modeling technique through this quote:

- "And that's essentially the problem of engineering we can never solve problems exactly, as engineers we make assumptions - and then we go back and check our assumptions."

In another class the Professor said:

- "We're going to have another lesson of being a professional engineer. When you make a mistake, you 'fess up to it. As a professional engineer you never cover up your mistakes - it makes for good TV drama, but that's not good for engineers!"

The researcher viewed this modeling as a powerful way to engage students. She spoke about it with the Professor during their interviews:

- "You had the equation, you had the system and then...you said now we're going to analyze this system...you set them up like engineers from the beginning, all the assumptions you had to make..."

And at another time:

- "well I just thought that was great...I felt like I was sitting in a room [full] of engineers."

\subsection{Strategies Particular to the Instructor}

The strategies that were particular to the Professor were mainly observed in the study and pointed out as instructional strengths. They were his use of: (i) Humour; (ii) Movement; and (iii) Stories. There was no real need to 
modify these strategies as they were used effectively; rather, the researcher encouraged their use, and as a result their frequency increased.

(i) Humour: The Professor laughed and smiled frequently, and made quips and funny remarks. The Professor naturally used humour as a teaching strategy, as illustrated in the examples below.

- "How many think the state is defined? How many don't? How many don't have a clue?"

- The Professor asked students a "yes, no, maybe" question, and then said in response to them all, "You're all wrong!"

- The Professor displayed huge text boxes on his slides that said: "BIG THERMODYNAMIC WARNING!"; "SUPER BIG THERMO FACT"; "SUPER DUPER BIG THERMO FACT!" and "BIG THERMODYNAMIC PAT ON THE BACK!"

- The Professor's last slide in the last class said: "Here Endeth the Lesson(s)!"

Sometimes the Professor's humour would call attention to the age difference between him and his students. For example, he referenced the television show "Sesame Street," which was first aired in 1969, and the film "Mad Max Beyond Thunderdome," released in 1985. At these times, the Professor realized he had created a generation gap, and was able to laugh at himself. The use of humour was a strategy that the professor capitalized on to promote student engagement.

(ii) Movement: The Professor moved up and down the aisles in close proximity to the students, and down across the front of the room throughout the instruction. He would stop on each side of the room to ask a question or explain a problem, or stop in front to point to a slide. He used eye contact continually. The Professor observed if the students followed his movements, and he used these physical strategies and proximity to encourage student engagement.

(iii) Stories: The Professor used a number of stories to connect students from the problems on the slides to real world examples. He discussed boiling an egg on Mt. Everest; how many calories he would burn by taking the stairs in the building instead of the elevator; the size of steam plants in America versus Canada; the 21 lanes of traffic in Houston, and numerous other stories illustrating authentic application of engineering situations/problems. For example:

- "Some of you are going to go into electrical engineering...I'm going to tell you a secret about electrical engineering..."
- "When James Watt made the first steam engines, they were running at $100 \mathrm{~s}$ of $\mathrm{kPa}$ and now they're running at over a $\mathrm{MPa}$... and that was done by design...better science...driven science. This is driven science, driven engineering."

- "We're blessed in Manitoba - we have hydro and wind...We're throwing away $80 \%$ of our fuel...this simple example shows us how wasteful we actually are...which is a big argument for renewables... Now if you think this is bad, look at the engine of your car...There's only so much coal, only so much oil. When it's gone, it's gone. [Let me tell you a] story about Houston: 4 hours in the morning and 4 hours at night 21 lanes into Houston was bumper to bumper...and the carpool lanes were virtually empty. I think society has a real problem..."

The Professor relayed his stories to connect students to real world situations and foster student engagement.

\section{CONCLUSIONS AND NEXT STEPS}

This research was initiated as a qualitative pilot study guided by action research and ethnographical methodologies. The objectives were to (i) investigate the Professor's instructional strategies to incorporate active learning and encourage student engagement; and (ii) make improvements to these strategies to increase active learning and student engagement. A wealth of data was produced as a result of this study. Details emerged from the data evidencing how the Professor's instructional strategies were enhanced to incorporate more active learning and encourage student engagement. These included:

- Improved questioning techniques: particularly the distinction between rhetorical and Socratic style questions;

- Increased active learning opportunities: students solved problems, did interpolations, and wrote down equations in class;

- Increased cooperative learning opportunities: students engaged in discussions with their peers;

- Increased learner independence: through in-class problem solving and methods of gradual release, students were coaxed to be more independent problemsolvers;

- Increased presence of transparent teaching objectives: the use of road mapping paved the way for added learner engagement and responsibility;

- Improved instructional materials: revised class slides boosted problem solving opportunities and the potential for learner independence; the Flow Device handout replaced lectures;

- Evolution of instructional tools: the i-clicker generated student and instructor instant feedback. It was a 
"temperature check" of class climate and level of understanding;

- Increased Professor-student-learning connections: the conscientious use of personal and professional anecdotes was used to connect students to the learning and amplify engagement; the conscious references to the thinking, assumptions, knowledge, skills and values inherent to being a professional engineer was done to authenticate students' instructional experience and to invite engagement.

The researcher's reflective notes taken during participant observations further highlight the Professor's intentions to increase student engagement:

- It's a nice balance of engagement and letting students be adults - [the Professor] "invites" engagement, rather than demanding it. He's spoken about his philosophy about his students being adults and that he must treat them as such - this is evident in his teaching style. I feel a sense of excitement about the good teaching practice [to foster] student engagement!

This study has provided opportunities for continued investigation. They are:

1)A research study is planned for the Professor's next ENG 1460 course. The Professor will alternate lectures and tutorials within each class. Participant observations, interviews, a student survey and student focus group interviews are proposed in order to explore students' perceptions and experiences in regards to the Professor's use of instructional strategies to promote active learning and student engagement. The ethics application to the faculty's ethics board (ENREB) is currently being processed.

2)The Professor is still working towards having experimental apparatuses built for demonstration purposes for ENG 1460. He is convinced that this is another key to engagement in this course. This will be an additional area for future exploration.

Research has shown that "engagement is both a process and an outcome. Faculty stimulate engagement by providing students with active learning experiences, conveying excitement and enthusiasm for their subject, and providing opportunities for student-faculty interactions" [6]. In this pilot study, the Professor employed active learning strategies, showed his passion for engineering, and used personal and professional anecdotes to connect with his students and stimulate student engagement.

\section{Acknowledgements}

This research study was funded by the NSERC Chair in Design Engineering program at the University of
Manitoba, and Dr. Ingram's University of Manitoba Faculty of Engineering Start-up Grant. The authors of this paper would also like to acknowledge Paul Labossiere for his technical support.

\section{References}

[1] Jennifer M. Case and Gregory Light, "Emerging methodologies in engineering education research," Journal of Engineering Education, vol. 100, no.1, pp. 186-210, 2011.

[2] Helen L. Chen, Lisa R. Lattuca and Eric R. Hamilton, "Conceptualizing engagement: Contributions of faculty to student engagement in engineering," Journal of Engineering Education, vol. 97, no. 3, pp. 339-353, 2008.

[3] John W. Creswell, Qualitative Inquiry and Research Design: Choosing Among Five Approaches. Thousand Oaks, CA: Sage Publications, 2007, (2nd ed.), 395 pp.

[4] Douglas Duncan, "Clickers: A new teaching aid with exceptional promise," Chemistry Education Research and Practice, issue 3, 2008. Available from

http://pubs.rsc.org/en/content/articlelanding/2008/rp/b812407h

[5] Marcia Friesen and Sandra Ingram, "Advancing intercultural competency: Canadian engineering employers' experiences with immigrant engineers," European Journal of Engineering Education, pp. 1-9, 2013. Available from http://dx.doi.org/10.1080/03043797.2013.766677

[6] Rachelle S. Heller, Cheryl Beil, Kim Dam, and Belinda Haerum, "Student and faculty perceptions of engagement in engineering," Journal of Engineering Education, vol. 99, no. 3, pp. 253-261, 2010.

[7] E. Hohenberg, Personal communication. University of Manitoba, 2012.

[8] Philip W. Jackson, Life in Classrooms. New York, NY: Teachers College Press, 1990, 183 pp.

[9] Aditya Johri and Barbara M. Olds, "Situated engineering learning: Bridging engineering education research and the learning sciences," Journal of Engineering Education, vol. 100, no. 1, pp. 151-185, 2011.

[10] Ellin Oliver Keene and Susan Zimmermann, Mosaic of Thought: The Power of Comprehension Strategy Instruction. Portsmouth, NH: Heinemann, 2007 (2nd ed.), 312 pp.

[11] Mirka Koro-Ljungberg and Elliot P. Douglas, "State of qualitative research in engineering education: Meta-analysis of JEE articles, 2005-2006," Journal of Engineering Education, vol. 97, no. 2, pp. 163-175, 2008.

[12] Thomas A. Litzinger, Lisa R. Lattuca, Roger G. Hadgraft and Wendy C. Newstetter, "Engineering education and the development of expertise," Journal of Engineering Education, vol. 100, no. 1, pp. 123-150, 2011. 
[13] Jon A. Leyden, Barbara M. Moskal and Michael J. Pavelich, "Qualitative methods used in the assessment of engineering education," Journal of Engineering Education, vol. 93, no. 1, pp. 65-72, 2004.

[14] Richard E. Mayer, Andrew Stull, Krista DeLeeuw, Kevin Almeroth, Bruce Bimber, Dorothy Chun, Monica Bulger, Julie Campbell, Allan Knight and Hangin Zhang, "Clickers in college classrooms: Fostering learning with questioning methods in large lecture classes," Contemporary Educational Psychology, vol. 24, no 1., pp. 51-57, 2009. Available from http://www.sciencedirect.com/science/article/pii/S0361476X 08000295

[15] Barbara M. Olds, Barbara M. Moskal and Ronald L. Miller, "Assessment in engineering education: Evolution, approaches and future collaborations," Journal of Engineering Education, vol. 94, no. 1, pp. 13-25, 2005.

[16] Marie C. Paretti, "Teaching communication in capstone design: The role of the instructor in situated learning," Journal of Engineering Education, vol. 97, no. 4, pp. 491512,2008 .

[17] Alice Pawley, "Universalized narratives: Patterns in how faculty members define "engineering", Journal of Engineering Education, vol. 98, no. 4, pp. 309-319, 2009.

[18] Michael J. Prince and Richard M. Felder, "Inductive teaching and learning methods: Definitions, comparisons, and research bases," Journal of Engineering Education, vol. 95, no. 2, pp.123-138, 2006.

[19] Johnny Saldana, The Coding Manual for Qualitative
Researchers. Thousand Oaks, CA: SAGE, 2009, 223 pp.

[20] Karl A. Smith, Sheri D. Sheppard, David W. Johnson and Roger T. Johnson, "Pedagogies of engagement: Classroombased practices," Journal of Engineering Education, vol. 94, no. 1, pp. 87-101, 2005.

[21] Reed Stevens, Kevin O'Connor, Lari Garrison, Andrew Jocuns, and Daniel M. Amos, "Becoming an engineer: Toward a three dimensional view of engineering learning, Journal of Engineering Education, vol. 97, no. 3, pp. 355$368,2008$.

[22] Karen L. Tonso, "Student learning and gender," Journal of Engineering Education, vol. 100, no. 2, pp. 143-150, 1996.

[23] Karen L. Tonso, "The impact of cultural norms on women," Journal of Engineering Education, vol. 100, no. 3, pp. 217$225,2011$.

[24] Christina M. Vogt, "Faculty as a critical juncture in student retention and performance in engineering programs," Journal of Engineering Education, vol. 97, no. 1, pp. 27-36, 2008.

[25] Aman Yadav, Dipendra Subedi, Mary A. Lundeberg and Charles F. Bunting, "Problem-based learning: Influence on students' learning in an electrical engineering course," Journal of Engineering Education, vol. 100, no. 2, pp. 253$280,2011$.

[26] Joseph S. Wholey, Harry P. Hatry and Kathryn E. Newcomer (eds.), Handbook of Practical Program Evaluation. San Francisco, CA: Jossey-Bass, 2010 (3rd ed.), $710 \mathrm{pp}$. 